\title{
BMJ Open Economic impact of delirium in Australia: a cost of illness study
}

\author{
Lynne Pezzullo, ${ }^{1}$ Jared Streatfeild, ${ }^{\circ 1}$ Josiah Hickson, ${ }^{1}$ Andrew Teodorczuk, ${ }^{2}$ \\ Meera R Agar, ${ }^{3}$ Gideon A Caplan ${ }^{4,5}$
}

To cite: Pezzullo L, Streatfeild J, Hickson J, et al. Economic impact of delirium in Australia: a cost of illness study. BMJ Open 2019;9:e027514. doi:10.1136/ bmjopen-2018-027514

- Prepublication history and additional material for this paper are available online. To view please visit the journal (http:// dx.doi.org/10.1136/bmjopen2018-027514).

Received 29 0ctober 2018 Revised 26 July 2019

Accepted 14 August 2019

Check for updates

(C) Author(s) (or their employer(s)) 2019. Re-use permitted under CC BY-NC. No commercial re-use. See rights and permissions. Published by BMJ.

${ }^{1}$ Deloitte Access Economics, Canberra Airport, Australian Capital Territory, Australia

${ }^{2}$ School of Medicine, Griffith

University, Southport,

Queensland, Australia

${ }^{3}$ Improving Palliative, Aged and

Chronic Care through Clinical

Research and Translation,

University of Technology Sydney,

Ultimo, New South Wales,

Australia

${ }^{4}$ Department of Geriatric

Medicine, Prince of Wales

Hospital, Sydney, New South

Wales, Australia

${ }^{5}$ Prince of Wales Clinical School, University of New South Wales, Sydney, New South Wales, Australia

Correspondence to Jared Streatfeild;

jstreatfeild@deloitte.com.au

\section{ABSTRACT}

Objectives To estimate the economic impact of delirium in the Australian population in 2016-2017, including financial costs, and its burden on health.

Design, setting and participants A cost of illness study was conducted for the Australian population in the 2016-2017 financial year. The prevalence of delirium in 2016-2017 was calculated to inform cost estimations. The costs estimated in this study also include dementia attributable to delirium.

Main outcome measures The total and per capita costs were analysed for three categories: health systems costs, other financial costs including productivity losses and informal care and cost associated with loss of well-being (burden of disease). Costs were expressed in 2016-2017 pound sterling ( $($ ) and Australian dollars ( $\$ \mathrm{~A})$.

Results There were an estimated 132595 occurrences of delirium in 2016-2017, and more than 900 deaths were attributed to delirium in 2016-2017. Delirium causes an estimated $10.6 \%$ of dementia in Australia. The total costs of delirium in Australia were estimated to be $£ 4.3$ billion (\$A8.8 billion) in 2016-2017, ranging between £2.6 billion (\$A5.3 billion) and £5.9 billion (\$A12.1 billion). The total estimated costs comprised financial costs of $£ 1.7$ billion and the value of healthy life lost of $£ 2.5$ billion. Dementia attributable to delirium accounted for $£ 2.2$ billion of the total cost of delirium.

Conclusions These findings highlight the substantial burden that delirium imposes on Australian society - both in terms of financial costs associated with health system expenditure and the increased need for residential aged care due to the functional and cognitive decline associated with delirium and dementia. To reduce the substantial well-being costs of delirium, further research should seek to better understand the potential pathways from an episode of delirium to subsequent mortality and reduced cognitive functioning outcomes.

\section{INTRODUCTION}

Delirium is a common, serious and sometimes fatal medical condition, characterised by an acute decline in cognitive functioning. ${ }^{1}$ The term delirium is used to describe a transient, reversible neuropsychiatric syndrome that is of acute (abrupt or sudden) onset, with a fluctuating course which often occurs in the setting of a medical condition. ${ }^{2}$ The Diagnostic and Statistical Manual of Mental Disorders, Fifth Edition characterises delirium as
Strengths and limitations of this study

This cost of illness study estimates the total annual financial and well-being impacts of delirium for the first time in Australia.

- This study also estimates the costs of dementia that are associated with delirium in Australia, with significant implications for other high-income western countries.

- This study is based on a non-systematic search strategy to find relevant cost inputs, noting that a number of inputs are sourced from official Australian Government statistics.

- There were a number of data gaps when estimating costs, meaning the results of this study are only indicative of the total cost.

- While this cost of illness study estimates the overall cost of delirium, more work is needed to identify cost-effective interventions to reduce the burden of delirium.

a disturbance in attention, where the disturbance develops over a short period of time and represents an acute change from baseline attention and awareness. The disturbance should not be better explained by a pre-existing disorder, and evidence is required that the disturbance is a direct physiological consequence of another medical condition, substance intoxication or withdrawal or exposure to a toxin. ${ }^{3}$

The development of delirium has been associated with increased morbidity, persistent functional decline, higher hospital costs, higher rates of residential aged care placement and increased mortality. ${ }^{2}{ }^{45}$ It is also a significant risk factor for later onset of dementia and acceleration of cognitive decline. ${ }^{4}$ Though underdiagnosed, it is highly prevalent in hospitalisations, particularly so for palliative care populations ${ }^{6} 7$; as many as $50 \%$ of people over the age of 65 who are admitted to hospital experience delirium depending on the clinical setting. ${ }^{2}$ Despite being preventable in more than a third of cases, a study in Sweden showed that delirium 
remains a common complication in hospitalised elderly patients. $^{8}$

A previous study in the USA, undertaken over a decade ago, assessed the costs associated with delirium after adjusting for patient sociodemographic and clinical characteristics and found that hospital costs per day for patients with delirium were more than double the costs of patients who did not experience an episode of delirium. ${ }^{9}$ Additionally, previous studies have found associations between delirium and long-term cognitive impairment and dementia ${ }^{10}$ and premature death. ${ }^{3}{ }^{11}$ However, the relative costs of these outcomes have not yet been established.

To date, no studies have estimated the costs of delirium in Australia. Understanding the costs of delirium is important because delirium is often missed in as many as two-thirds of cases ${ }^{12}$ although there are validated tools for diagnosing delirium such as the Confusion Assessment Method. ${ }^{2}$

By better understanding the costs, morbidity and mortality of delirium, it is possible to answer the question of whether it would be worthwhile to pay more attention to its prevention and diagnosis. Understanding the costs of delirium also helps to make informed decisions regarding treatment interventions. The purpose of this study was to raise awareness of the impacts of delirium and contribute to improving policy in this area by quantifying the magnitude of the economic burden associated with delirium in Australia in 2016-2017.

\section{METHODS}

This cost of illness study was conducted using standard methodology, ${ }^{13}$ based on a prevalence approach to cost measurement. Prevalence approaches measure the number of people with a given condition in a base period and the costs associated with treating them, as well as other financial and non-financial costs in that year due to the condition. This approach was combined with both bottom-up and top-down approaches to estimate expenditure for each cost component. ${ }^{13}$ For example, a top-down approach was used to estimate the costs of dementia due to delirium, while most costs of delirium have been established using a bottom-up approach. The methodology is consistent with previously published research in this field in Australia and internationally. ${ }^{14-16}$ Costs were estimated from the perspective of Australian society for the 20162017 financial year.

In this study, the financial costs of delirium to the Australian health system include the costs of running hospitals and nursing homes, general practitioner (GP) and specialist services reimbursed through Australia's universal health insurance scheme and private funds, the cost of pharmaceuticals and over-the-counter medications, allied health services, research and health administration. The other financial costs of delirium in this study include productivity costs, informal care, funeral costs and deadweight losses associated with taxation payments and administration. The loss of well-being due to delirium was measured using disability adjusted life years (DALYs).

A targeted literature review was conducted to identify the prevalence of delirium in acute hospitalisations, nursing homes and in the community (without presenting to hospital). The review also covered costs, productivity and other outcomes (eg, mortality and burden of disease) due to delirium. The targeted review was investigative in nature and considered fit-for-purpose as the prevalence and methods vary widely across studies. Searches were conducted using PubMed in June 2017.

Studies were included if they were conducted in a hospital setting, and covered general hospital wards (medical or surgical) reflective of an acute setting. Studies were also included if they included costs of delirium, including health system, productivity, carer and well-being costs. Studies were excluded from the analysis if they did not measure prevalence using validated diagnostic measures, or if they did not report on costs or outcomes from delirium. Studies were further excluded if they did not report on primary or administrative data. No specific date restrictions were applied to the literature review due to the investigative nature of it. The specific search terms used in the literature review are available in online supplementary additional file 1 .

Results from the literature searches were generally pooled by taking a weighted average of outcomes or results. Additional grey literature (eg, government statistics) were also collated and these documents provide many of the necessary inputs for this cost of illness study.

\section{Prevalence}

The prevalence of delirium in Australian hospitals was estimated by taking a weighted average across identified studies (see online supplementary additional file 1, table 1 ). Prevalence was then applied to overnight acute emergency hospital separations for people aged 70 years or older in 2016-17 to estimate separations due to delirium in elderly people in that year. ${ }^{17}$

The number of separations in younger age groups (less than 70 years old) where delirium is recorded as an additional diagnosis were estimated by applying the ratio between total and principal delirium diagnoses to principal diagnoses in the younger age groups. ${ }^{17} 18$

No prevalence studies in Australian nursing homes were identified. Prevalence results were thus derived from a study from the Netherlands, ${ }^{19}$ due to similarities in aged care settings, demographic profiles and medication prescribing rates - for example, both countries exhibit high rates of psychotropic medication prescribing (though there are some differences in the preferred antipsychotic agent),${ }^{20}$ despite their limited efficacy and adverse effects in people with delirium. ${ }^{7}$ The combined prevalence and incidence was $8.5 \%$ and 16.9 per 100 person-years respectively. These rates are similar to the rates reported in other international literature. ${ }^{21-23}$ These rates were applied to the number of permanent residents in aged care facilities in Australia, adjusting 
for population growth by age group from the Australian Bureau of Statistics (ABS). ${ }^{24}$

The total prevalence of delirium in Australia 2016-17 was adjusted to avoid double counting people in the residential aged care cohort who also present to hospital. The following rates were used to adjust the prevalence to avoid double counting people in residential aged care who also present to hospital: $50 \%$ of cases were delirious at admis$\operatorname{sion}^{25} ; 43 \%$ of hospitalised patients with delirium during their stay were delirious at discharge $(5.5 \%$ delirious at discharge, $12.7 \%$ with delirium) ${ }^{26} ; 31.2 \%$ were admitted from residential aged care while $68.9 \%$ were admitted from the community ${ }^{27}$; and of people with delirium, $28 \%$ of patients were discharged to residential aged care, $63 \%$ were discharged to the community, and $9 \%$ died before discharge from hospital. ${ }^{28}$

\section{Average duration of an episode of delirium and mortality}

The average duration of delirium was estimated by taking a weighted average of the findings reported in twelve studies (online supplementary additional file 1, table 2).

Mortality associated with delirium was estimated using an attributable fraction approach, ${ }^{13}$ and a HR of 1.77 that was based on a previous systematic review and meta-analysis (online supplementary additional file 1 , table 3 ). ${ }^{3}$ The HR was used to estimate an attributable fraction for how many deaths are due to delirium in Australia.

\section{Healthcare system expenditure}

Health system costs were estimated using a bottom-up approach. This includes costs associated with hospital, medication, and research expenditure, out of hospital medical and other health professionals' expenditure, and residential aged care expenditure. Delirium induces functional decline, resulting in a longer length of stay (LOS) for older people in hospital, consequently leading to higher hospitalisation expenditure. ${ }^{2}$ To estimate the additional expenditure, the prevalence of delirium among hospitalised older people was applied to the additional LOS and the average daily cost of care in a hospital setting.

The average daily cost of an acute separation was obtained from the Independent Hospital Pricing Authority (IHPA) for 2014-15 and adjusted by the standard index rate used by IHPA $(2.1 \%)$ to estimate the cost for the 2016-17 base year. ${ }^{29}$ The average daily cost was also adjusted by an additional $14.3 \%$ to inflate for non-allocated health costs (an allowance for capital costs) based on AIHW. ${ }^{30}$

Delirium can also be recorded as an additional diagnosis in Australian hospital data, where delirium contributes to a greater length of stay in hospital. The cost associated with an increased length of stay was estimated using the average daily cost of any hospital separation, which was further adjusted to remove separation costs that are unlikely to be attributable to delirium, such as costs associated with surgery. Where delirium was a primary diagnosis, the cost was assumed to be the same as the delirium diagnostic resource group, which was $£ 4489$ in 2016-17 after updating for inflation in the National Efficient Price. ${ }^{29}$

Health research expenditure on delirium in Australia in 2016-17 was estimated using data from the National Health and Medical Research Council (NHMRC) grants database. The database outlines all NHMRC research grant funding between 2000 and 2016 and provides a description of the projects and key outcomes achieved. ${ }^{31}$ Annual funding allocated to delirium research in 2016-17 was estimated by taking an average across the historical years. Other forms of health research where research costs can be recovered - for example, by charging a higher price for services - were not considered in this analysis, consistent with standard methodology. ${ }^{13}$

Out of hospital medical expenditure (GP consultations) was estimated by applying the average cost per GP consultation (approximately $£ 16$ after adjusting for multiple problems per GP consultation) to the total services associated with organic psychoses in Australia, ${ }^{32} 33$ which was considered comparable to delirium.

Residential aged care expenditure was estimated using an attributable fraction approach based on literature to estimate admissions to aged care due to cognitive decline associated with delirium. The OR for admission (2.41), ${ }^{4}$ was converted to an attributable fraction. The number of admissions was adjusted by average LOS in residential aged care in Australia and applied to the average costs associated with residential aged care, which is approximately $£ 43978$ per person in aged care. ${ }^{34}$

\section{Other financial costs}

The economic cost of short run productivity losses associated with absenteeism were estimated using the friction cost method. ${ }^{13}$ The absenteeism cost due to delirium was estimated by multiplying the average duration of delirium by the number of hospital separations that occur in the working age population, adjusted for general population employment rates. Average employment rates and average weekly earnings for people with delirium are based on ABS data for the general population by age and gender. ${ }^{35} 36$

Carers are people who provide care to others in need of assistance or support. An informal carer provides this service without formal payment and does so outside of the formal care sector. Evidence suggests that people with delirium experience a decline in functioning, such that they are unable to perform as many usual activities of daily living following delirium. ${ }^{37} 38$ Estimates of the hours of informal care provided to people with delirium was based on this expected decline in activities of daily living. The dollar value of informal care was estimated as the opportunity cost of a carer's time, which was based on general population average weekly earnings and employment rates. ${ }^{35} 36$

The additional cost of funerals borne by family and friends of people with delirium was based on the number of deaths associated with delirium. The cost of a funeral 
was assumed to be $£ 4602$. Funeral costs were brought forward by the average life expectancy at age of death. The deadweight losses due to lost taxation revenue (given an assumption of no change in spending) and additional government spending on delirium was calculated by applying the average marginal excess burden of taxation of $£ 0.31$ per $£ 1$ of tax. ${ }^{39} 40$

\section{Loss of well-being}

Burden of disease methodology was employed to quantify the impact of delirium on well-being. ${ }^{41}$ The approach is non-financial, where pain, suffering and premature mortality are measured in terms of disability adjusted life years (DALYs). DALYs are comprised of years of healthy life lost due to morbidity (YLDs) and years of life lost due to premature mortality (YLLs). ${ }^{41}$ YLDs were calculated using a prevalence approach, whereby the disability weight was multiplied by average duration of delirium. The disability weight for delirium used in this study was $0.17 .^{42}$ Duration of delirium was based on the prevalence of persistent delirium over 12 months. ${ }^{43}$ DALYs were converted to a monetary value using the value of a statistical life year ( $£ 93882$ ), which is an official estimate updated for inflation using the Consumer Price Index. ${ }^{44}$ The value of a statistical life year was discounted at a rate of $3 \%$ per annum, ${ }^{13}$ where it was applied to future years of life lost due to mortality from delirium.

\section{Costs of dementia attributable to delirium}

Costs of dementia were sourced from an Australian cost of illness study. ${ }^{45}$ Inputs were taken for Australia in the 2016 financial year, and updated using either health inflation or the Consumer Price Index as appropriate. The well-being cost attributable to dementia for YLLs or YLDs was estimated using data from the Australian Institute of Health and Welfare's Australian Burden of Disease Study. ${ }^{46}$ The proportion of dementia attributable to delirium was estimated using the population attributable fraction approach. The OR for developing a new case was 5.88 for people aged $65-84$ years old and 7.56 for people aged 85 years or older, ${ }^{47-49}$ which was used to estimate the attributable fraction.

\section{Sensitivity analysis}

One-way sensitivity analyses were conducted on prevalence, the risk for mortality, dementia admission to aged care, average hospital costs, discount rate for DALYs, and the value of a statistical life year. The specific values represent the upper and lower 95\% confidence intervals for the relevant input parameters where available, or unit costs that were $25 \%$ higher or lower if the distribution was unknown.

\section{Currency standardisation}

All costs are expressed in 2016-17 pound sterling. Costs were converted from Australian dollars using the 2017 Organisation for Economic Cooperation and Development purchasing power parity of 2.065 Australian dollars per pound sterling in $2017 .^{50}$

\section{Data analysis and ethical considerations}

Data for this study was collected throughout January to June 2017 by the authors from a range of public data sources and literature. The data was analysed and compiled in Microsoft Excel. No individual patient data was collected for the study and therefore, this study did not require ethics approval.

\section{Patient and public involvement}

Patient and public were not involved in the design or planning of this study.

\section{RESULTS}

\section{Prevalence and mortality}

Overall, the prevalence of delirium in a hospital setting was estimated to be $20.2 \%$ on average, which was applied to the 521099 overnight acute emergency hospital separations for people aged 70 years or older in 2016-17. Therefore, there were an estimated 105182 hospital separations involving delirium in 2016-17, of which delirium was recorded as the principal diagnosis for approximately 11999 separations in 2016-17. In addition, there were an estimated 14578 separations for younger Australians, and 119760 total cases of delirium in Australian hospitals in 2016-17.

In Australia on 30 June 2015, there were 172044 permanent residents in aged care facilities. There were an estimated 181314 permanent residents in Australian aged care facilities on 30 June 2017 after adjusting for population growth by age group. Applying the prevalence (at baseline), and the incidence per 100 person years from Boorsma et $a l,{ }^{19}$ it was estimated that 46054 permanent residents had at least one episode of delirium in 2016-17.

After adjusting for the interactions between delirium in aged care and hospital settings, there were an estimated 132595 cases of delirium in Australia in 2016-17, representing cases that occur in both settings. This is equivalent to approximately $0.5 \%$ of the population in Australia, although some individuals may experience delirium more than once in a year. Prevalence by age and gender are available in table 1 . The rates increase substantially with age.

The HR for mortality indicated that 12571 people who had delirium would die, and an estimated 909 deaths were attributable to delirium itself in 2016-17.

\section{Healthcare system expenditure}

Delirium most commonly occurred in hospitals in Australia in 2016-17, with an estimated 119760 cases (some of these individuals usually reside in aged care). Delirium was recorded as the primary diagnosis in 13662 separations at an average cost of $£ 4489$ per separation in 2016-17. Delirium was recorded as an additional diagnosis in a further 106098 separations. The average daily cost for an additional separation was estimated to be $£ 644$, which was multiplied by the number of cases and the additional LOS due to delirium, which was estimated to be 2.7 


\begin{tabular}{|c|c|c|c|c|}
\hline $\begin{array}{l}\text { Age/ } \\
\text { gender }\end{array}$ & Community & $\begin{array}{l}\text { Residential } \\
\text { aged care }\end{array}$ & Total & $\begin{array}{l}\% \text { of } \\
\text { general } \\
\text { population }\end{array}$ \\
\hline \multicolumn{5}{|l|}{ Male } \\
\hline$<65$ & 3278 & 1756 & 5034 & 0.05 \\
\hline $65-69$ & 1916 & 1281 & 3197 & 0.5 \\
\hline $70-74$ & 4342 & 2088 & 6430 & 1.4 \\
\hline $75-89$ & 6282 & 2868 & 9149 & 2.8 \\
\hline 80-84 & 9680 & 3545 & 13225 & 6.3 \\
\hline $85+$ & 18651 & 3263 & 21914 & 11.8 \\
\hline Total & 44149 & 14801 & 58949 & 0.5 \\
\hline \multicolumn{5}{|l|}{ Female } \\
\hline$<65$ & 4100 & 746 & 4846 & 0.05 \\
\hline 65-69 & 1994 & 778 & 2773 & 0.5 \\
\hline $70-74$ & 4044 & 1523 & 5567 & 1.1 \\
\hline $75-79$ & 6224 & 2771 & 8996 & 2.5 \\
\hline $80-84$ & 9195 & 5270 & 14465 & 5.5 \\
\hline $85+$ & 16835 & 20164 & 36999 & 11.9 \\
\hline Total & 42393 & 31253 & 73646 & 0.6 \\
\hline Person & 86541 & 46054 & 132595 & 0.5 \\
\hline
\end{tabular}

days (see online supplementary additional file 1, table 4 and table 5). After adjusting for population growth, there were estimated to be $22640 \mathrm{GP}$ consultations associated with delirium in 2016-17, which was multiplied by $£ 16$ per consultation to estimate total GP costs.

Total health system and aged care costs associated with delirium in Australia were estimated to be $£ 844.2$ million in 2016-17. The total comprised hospital ( $£ 247.3$ million), residential aged care ( 5596.2 million), out-of-hospital medical (£0.4million), and research expenditure (£0.3 million).

\section{Other financial costs}

On average, it was estimated that each person with delirium received an additional 0.9 hours of care per week, based on the change in activities of daily living over a period of 12 months (online supplementary additional file 1 provides supplementary information that was used to estimate the additional hours of care). Thus, informal carers provided an estimated 987958 hours of care in 2016-17, which was valued at $£ 0.8$ million. The cost of informal care ( $£ 0.8$ million) is relatively small due to the low opportunity cost of carer time (£0.84 per hour).

We estimate that working age people with delirium were absent from work for 44590 days in 2016-17, which was valued at $£ 6.6$ million using average weekly earnings for the general population.

Finally, brought forward funeral costs were estimated to be $£ 0.7$ million and deadweight losses were estimated to be $£ 188.4$ million in Australia 2016-17. Thus, total other financial costs (informal care, absenteeism, brought forward funeral costs and deadweight losses) were estimated to be £196.6million in Australia in 2016-17. Productivity losses imposed by delirium were estimated to be relatively small as delirium largely occurs in the elderly population.

\section{Loss of well-being}

The total burden of disease from delirium in 2016-17 was estimated to be $£ 994.1$ million. Overall, delirium resulted in an estimated: 5441 years of healthy life lost due to disability (YLDs), or 0.041 YLDs per person with delirium; 5687 years of life lost due to premature death (YLLs), or 0.043 YLLs per person with delirium; and 11128 DALYs overall, or around 0.084 DALYs per person with delirium in 2016-17.

\section{Costs of dementia attributable to delirium}

Overall, it was estimated that $40981(10.6 \%)$ cases of dementia were attributable to delirium, which largely occur in people aged 85 years or older. The total costs of dementia due to delirium were estimated to be $£ 2.2$ billion in Australia in 2016-17, of which the financial costs were $£ 675.7$ million and the loss of well-being was $£ 1.6$ billion. table 2 shows cost breakdowns by age and gender group. Figure 1 shows the costs of dementia due to delirium broken down by health system and aged care costs, other financial costs and burden of disease.

\section{Total costs}

The total costs of delirium in Australia were estimated to be $£ 4.3$ billion ( $\$$ A8.8 billion) in 2016-17. The total cost comprised financial costs of $£ 1.7$ billion ( $\$$ A3.5 billion) and the value of healthy life lost of $£ 2.5$ billion ( $\$$ A5.3 billion). table 3 shows the costs of delirium broken down by health system and aged care costs, other financial costs, and burden of disease.

\section{Sensitivity analysis}

The results and specific values for the sensitivity analysis are shown in table 4 and figure 2. The total cost of delirium in Australia was most sensitive to changes in the risk for dementia following delirium and the overall prevalence rate. The total cost of delirium was estimated to range from $£ 2.6$ billion to $£ 5.9$ billion in Australia in 2016-17.

\section{DISCUSSION}

This is the first cost of illness study estimating the economic impact of delirium in the Australian population. While a number of studies have examined the financial costs of delirium, they are generally limited to specific services or population subgroups. ${ }^{5}$ There have been no previous attempts to estimate the cost of delirium taking into account both the financial and well-being costs, as this study has done. It is critical that such economic estimations are undertaken as they inform decision making. 


\begin{tabular}{|c|c|c|c|c|c|c|}
\hline \multirow[t]{2}{*}{ Age/ gender } & \multicolumn{2}{|c|}{ Financial cost } & \multicolumn{2}{|c|}{ Well-being cost } & \multirow[t]{2}{*}{ Total } & \multirow[t]{2}{*}{$\%$ of total } \\
\hline & Delirium & Dementia due to delirium & Delirium & Dementia due to delirium & & \\
\hline \multicolumn{7}{|l|}{ Male } \\
\hline$<65$ & 15.0 & - & 19.5 & - & 34.5 & 1 \\
\hline $65-69$ & 8.1 & 7.9 & 12.6 & 5.1 & 33.7 & 1 \\
\hline $70-74$ & 57.5 & 22.3 & 26.8 & 18.2 & 124.8 & 3 \\
\hline $75-89$ & 81.9 & 48.2 & 43.7 & 67.6 & 241.4 & 6 \\
\hline $80-84$ & 124.6 & 67.9 & 89.5 & 126.3 & 408.4 & 10 \\
\hline $85+$ & 233.5 & 154.1 & 260.6 & 368.2 & 1016.3 & 24 \\
\hline \multicolumn{7}{|l|}{ Female } \\
\hline$<65$ & 14.7 & - & 18.7 & - & 33.4 & 1 \\
\hline $65-69$ & 7.0 & 9.8 & 10.8 & 7.2 & 34.8 & 1 \\
\hline $70-74$ & 52.2 & 14.6 & 22.4 & 13.8 & 103.0 & 2 \\
\hline $75-79$ & 81.0 & 47.1 & 39.7 & 72.2 & 240.0 & 6 \\
\hline $80-84$ & 121.9 & 71.1 & 80.3 & 144.0 & 417.4 & 10 \\
\hline $85+$ & 243.3 & 232.9 & 369.4 & 729.0 & 1574.6 & 37 \\
\hline Overall & 1040.8 & 675.7 & 994.1 & 1551.6 & 4262.2 & 100 \\
\hline$\%$ of total & 24 & 16 & 23 & 36 & 100 & \\
\hline
\end{tabular}

According to these estimates, delirium imposes a substantial burden on society. Considering delirium alone, the economic costs were mostly incurred by the health and aged care systems (£844.2 million), representing close to $1.5 \%$ of total expenditure on health and aged care in Australia. As many high-income western countries are dealing with issues of ageing demographics and cognitive impairment, the findings may be generalizable to other health and aged care systems. For example, previous research has found that delirium is associated with multiple adverse outcomes including increased length and cost of hospitalisation, functional and cognitive decline, institutionalisation, and mortality. ${ }^{2-5} 51$ These results have significant implications for governments, who aim to identify conditions with high social and financial costs for focused attention through public education and other initiatives that effect improvements in health status. The results of this study highlight the need for concerted, worldwide efforts to mitigate the impacts of this clinically significant and costly medical condition.

According to these estimates, there were 132595 occurrences of delirium in Australia in 2016-17, but data from the Australian Institute of Health and Welfare National Hospital Morbidity Database for 2015-16 indicate that as

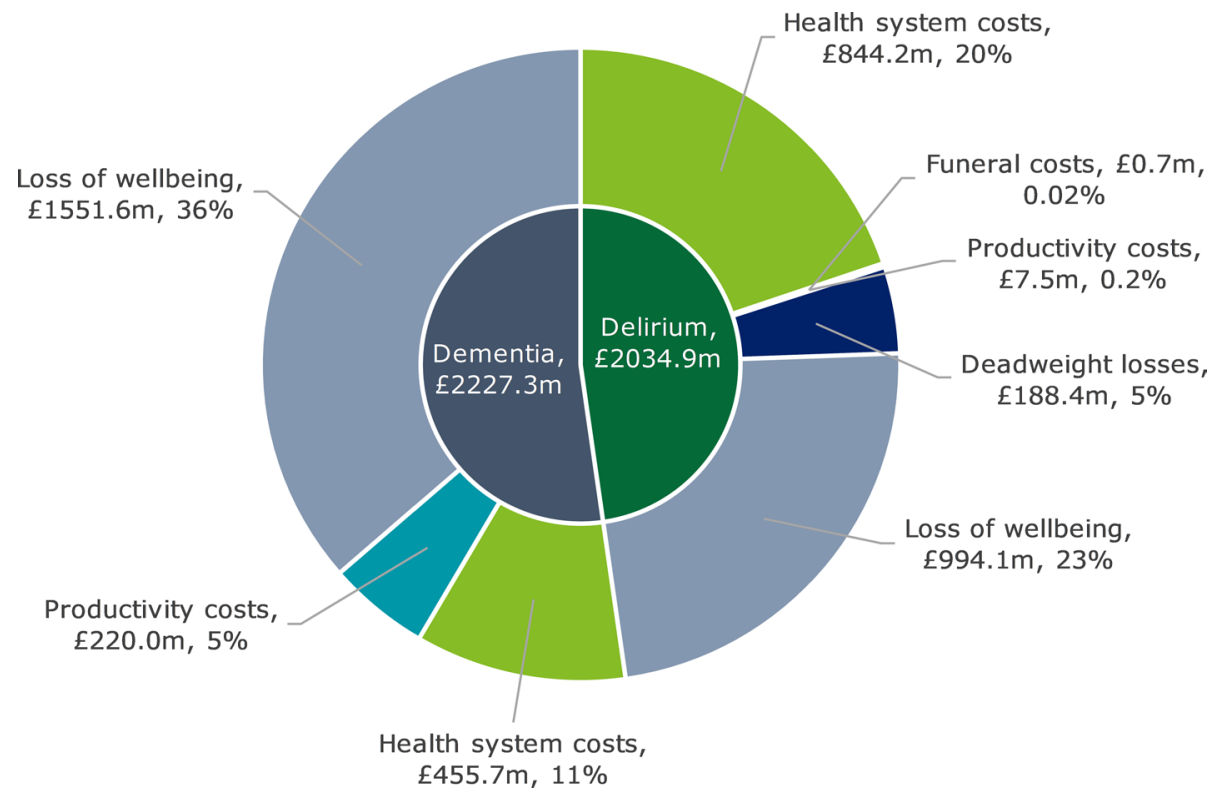

Figure 1 Costs of delirium and dementia due to delirium in Australia in 2016-17, £ million. 
Table 3 Estimated costs of delirium in Australia in 201617 , by cost component

\begin{tabular}{lcc}
\hline Cost component & $\begin{array}{l}\text { Total }(£ \\
\text { million) }\end{array}$ & $\begin{array}{l}\text { Per person with } \\
\text { delirium }(£)\end{array}$ \\
\hline Health system and aged care & 1299.9 & 9804 \\
Other financial costs & 416.6 & 3142 \\
Loss of well-being & 2545.7 & 19199 \\
Total costs & 4262.2 & 32145 \\
\hline
\end{tabular}

many as 1 in five cases are missed. This is supported by previous research which suggests that delirium is undiagnosed in a large number of cases, ranging from approximately $25 \%$ of cases up to $87.5 \%$ in cases where dementia is also present. ${ }^{12}$ This has significant implications for clinical practice as the outcomes of delirium are serious. ${ }^{1}$ Future research could focus on techniques to improve the detection rate.

\begin{tabular}{|c|c|c|c|}
\hline Variable & Financial & $\begin{array}{l}\text { Loss of } \\
\text { well-being }\end{array}$ & Total \\
\hline Base case & 1716.5 & 2545.7 & 4262.2 \\
\hline \multicolumn{4}{|l|}{ Prevalence $(20.2 \%)$} \\
\hline Lower (17.0\%) & 1333.3 & 2110.6 & 3443.9 \\
\hline Upper (23.3\%) & 2141.1 & 2993.6 & 5134.7 \\
\hline \multicolumn{4}{|l|}{$\begin{array}{l}\text { Risk for mortality } \\
(\mathrm{OR}=1.77)\end{array}$} \\
\hline Upper $(\mathrm{OR}=2.15)$ & 1716.8 & 2757.9 & 4474.8 \\
\hline Lower (OR=1.39) & 1716.2 & 2316.7 & 4032.9 \\
\hline
\end{tabular}

Risk for dementia (OR for $>65=5.88$, OR for $>85=7.56)$

\begin{tabular}{|c|c|c|c|}
\hline $\begin{array}{l}\text { Upper (OR for }>65= \\
20.70, \text { OR for }>85= \\
29.43 \text { ) }\end{array}$ & 2191.0 & 3678.2 & 5869.2 \\
\hline $\begin{array}{l}\text { Lower }(\text { OR for }>65= \\
1.69, \text { OR for }>85= \\
1.96)\end{array}$ & 1213.0 & 1372.8 & 2585.8 \\
\hline \multicolumn{4}{|l|}{$\begin{array}{l}\text { Risk for admission to } \\
\text { aged care }(O R=2.41)\end{array}$} \\
\hline Upper (OR=3.29) & 1993.3 & 2545.7 & 4539.0 \\
\hline Lower (OR=1.77) & 1453.8 & 2545.7 & 3999.6 \\
\hline \multicolumn{4}{|l|}{$\begin{array}{l}\text { Average hospital } \\
\text { costs }^{*}\end{array}$} \\
\hline Upper (+25\%) & 1794.7 & 2545.7 & 4340.4 \\
\hline Lower (-25\%) & 1638.4 & 2545.7 & 4184.1 \\
\hline \multicolumn{4}{|l|}{$\begin{array}{l}\text { Discount rate for } \\
\text { DALYs }(3 \%)\end{array}$} \\
\hline Upper (7\%) & 1716.5 & 2488.6 & 4205.1 \\
\hline Lower (0\%) & 1716.5 & 2596.3 & 4312.9 \\
\hline
\end{tabular}

*Hospital costs were varied for delirium only, not dementia.
Dementia represents a significant cost to the economy of all countries; the cost of dementia due to delirium is therefore an important cost component of delirium. It has been estimated that 47 million people are living with dementia globally, with costs of $£ 583$ billion in 2015 (original estimate converted from US dollars to pound sterling using purchasing power parity of 0.713$)^{50}{ }^{52}$; moreover, prevalence is expected to triple over the next three decades. ${ }^{52}$ Overall, the costs of dementia attributable to delirium more than doubled the total costs of delirium in Australia in 2016-17. It was estimated that approximately $10.6 \%$ of dementia cases, and thus costs, are associated with delirium. Therefore, delirium imposes a large cost burden on residential aged care, due to the high prevalence of dementia and the strong relationships between cognitive impairment and aged care. There may be considerable opportunities to prevent some of the worldwide burden of dementia and improve the fiscal sustainability of health systems in the face of ageing populations.

Care for delirium following discharge from hospital relies heavily on informal carers, who provided almost 1 million hours of care to people with delirium. As workforce participation increases and the propensity to care declines ${ }^{53}$ there is a risk that the care needs of people with delirium will either go unmet, or require additional government funding for aged care to meet their needs.

There are some limitations to this study. First, the methods outlined the use of a non-systematic search strategy, noting that this was fit-for-purpose when a number of inputs were derived from official Australian Government statistics. The estimates presented should be interpreted with this in mind. Second, limited studies were found with appropriate methods to robustly estimate the prevalence of delirium in Australian hospital settings, but also in community or residential aged care settings. In order to minimise the impact of this limitation and the risk of double counting across studies, the analysis focused on delirium which met the full diagnostic criteria. Similarly, data paucity in some areas, such as out-of-hospital medical costs and productivity losses (employment outcomes) means that total estimates may be conservative. Given the methodology, the costs of delirium presented in this paper should be treated as an estimate only. More research, including observational studies in Australian settings, is required to understand the true costs incurred by people with delirium. However, a study that can capture costs across the health system and aged care settings in Australia will be technically challenging and may not be feasible due to the fragmented nature of the systems and data collection particularly beyond the point at which people interact with the system. Finally, cost of illness studies provide guidance on the size of the problem, but are only useful for informing cost effective options for change when compared with the cost of such interventions. More work is needed to identify cost effective options to reduce the burden of delirium in Australia. 


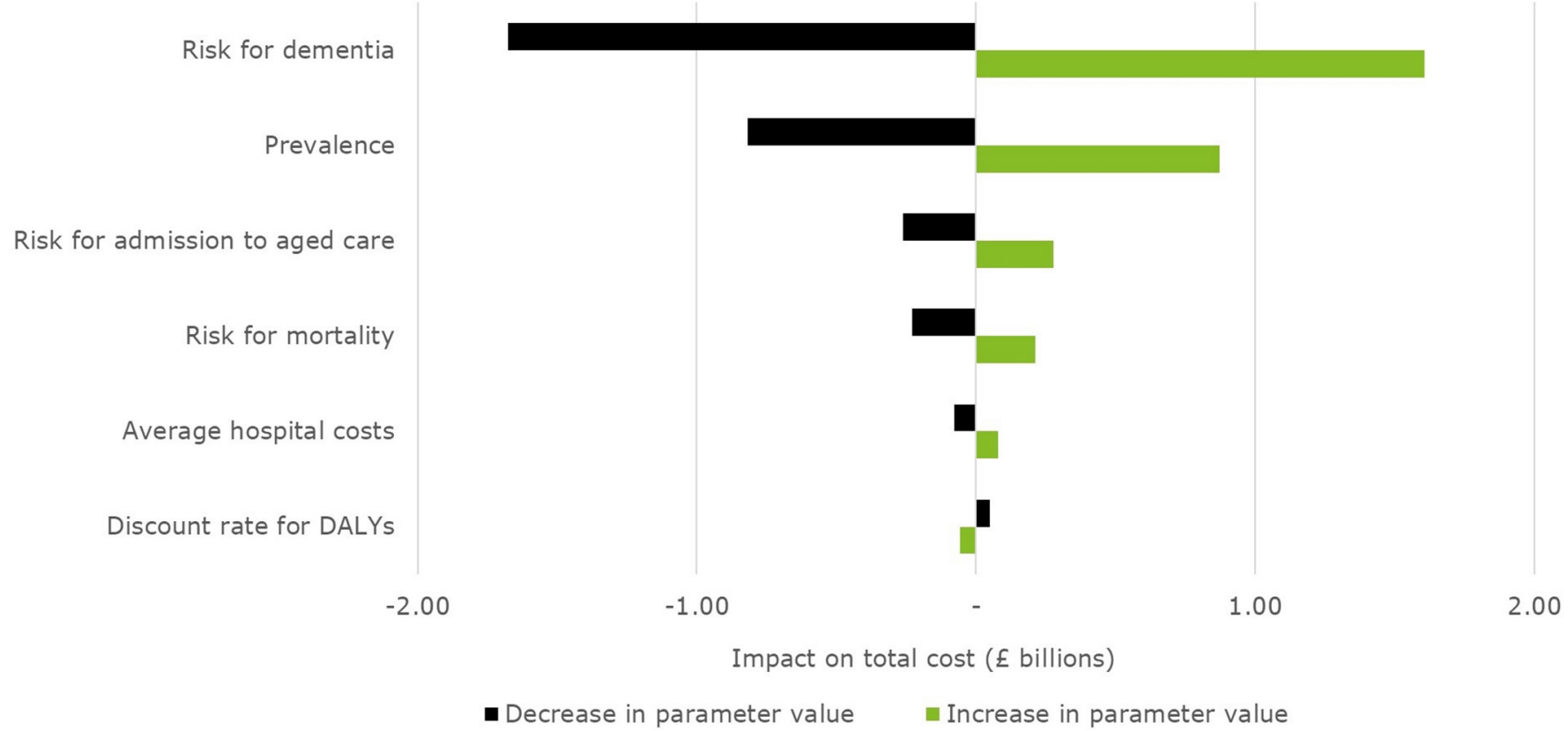

Figure 2 Sensitivity analysis (tornado diagram) showing the impact of key parameter inputs on the total cost of delirium in Australia in 2016-2017.

\section{CONCLUSION}

In summary, delirium imposes a substantial burden on Australian society - both in terms of financial costs associated with health system expenditure and a greater need for residential aged care due to the functional and cognitive decline associated with delirium and dementia. The financial costs of delirium were largely borne by Australian governments due to the health system and aged care expenditure.

Further research should seek to understand the causes, treatment and prognosis of delirium, especially with regard to potential pathways from an episode of delirium to subsequent mortality outcomes and reduced cognitive functioning. Improving mortality outcomes and reducing decline in cognitive functioning would help to reduce the substantial financial and well-being costs of delirium.

Contributors LP, JS and GAC conceived of and designed the study. JS, JH and LP collated the data, performed the data analysis and contributed to interpretation and reporting of the data. AT, MRA and GAC contributed to the interpretation and reporting of the data. All authors read, commented on and approved the final manuscript, and all authors reviewed the manuscript for important intellectual content. The sponsor was not directly involved in the findings of the research.

Funding The research was supported by the Australasian Delirium Association. Competing interests None declared.

Patient consent for publication Not required.

Provenance and peer review Not commissioned; externally peer reviewed.

Data availability statement All data relevant to the study are included in the article or uploaded as supplementary information.

Open access This is an open access article distributed in accordance with the Creative Commons Attribution Non Commercial (CC BY-NC 4.0) license, which permits others to distribute, remix, adapt, build upon this work non-commercially, and license their derivative works on different terms, provided the original work is properly cited, appropriate credit is given, any changes made indicated, and the use is non-commercial. See: http://creativecommons.org/licenses/by-nc/4.0/.

\section{REFERENCES}

1. Caplan GA, Kurrle SE, Cumming A. Appropriate care for older people with cognitive impairment in hospital. Med J Aust 2016;205:12-15.

2. Inouye SK, Westendorp RGJ, Saczynski JS. Delirium in elderly people. The Lancet 2014;383:911-22.

3. American Psychiatric Association. Diagnostic and statistical manual of mental disorders (DSM-5®). American psychiatric PUB 2013.

4. Witlox J, Eurelings LSM, de Jonghe JFM, et al. Delirium in elderly patients and the risk of postdischarge mortality, institutionalization, and dementia: a meta-analysis. JAMA 2010;304:443-51.

5. Leslie DL, Inouye SK. The importance of delirium: economic and societal costs. J Am Geriatr Soc 2011;59:S241-S243.

6. Siddiqi N, House AO, Holmes JD. Occurrence and outcome of delirium in medical in-patients: a systematic literature review. Age Ageing 2006;35:350-64.

7. Mittal V, Muralee S, Williamson D, et al. Review: delirium in the elderly: a comprehensive review. Am J Alzheimers Dis Other Demen 2011;26:97-109.

8. Johansson YA, Bergh I, Ericsson I, et al. Delirium in older hospitalized patients - signs and actions: a retrospective patient record review. BMC Geriatr 2018;18:43.

9. Leslie DLet al. One-Year health care costs associated with delirium in the elderly population. Arch Intern Med 2008;168:27-32.

10. Pandharipande PP, Girard TD, Jackson JC, et al. Long-Term cognitive impairment after critical illness. $N$ Engl J Med Overseas Ed 2013;369:1306-16.

11. Leslie DL, Zhang Y, Holford TR, et al. Premature death associated with delirium at 1-year follow-up. Arch Intern Med 2005;165:1657-62.

12. Speed G, Wynaden D, McGowan S, et al. Prevalence rate of delirium at two hospitals in Western Australia. Aust $J$ Adv Nurs 2007;25:38-43.

13. Segel JE. Cost-Of-IIIness studies- a primer. RTI-UNC center of excellence in health promotion economics, 2006. Available: https:// www.rti.org/sites/default/files/resources/COI_Primer.pdf [Accessed 11 Dec 2017].

14. Pezzullo L, Streatfeild J, Simkiss P, et al. The economic impact of sight loss and blindness in the UK adult population. BMC Health Serv Res 2018;18:63.

15. Hillman D, Mitchell S, Streatfeild J, et al. The economic cost of inadequate sleep. Sleep 2018;41:zsy083.

16. Taylor HR, Pezzullo ML, Keeffe JE. The economic impact and cost of visual impairment in Australia. Br J Ophthalmol 2006;90:272-5.

17. Australian Institute of health and welfare (AlHW). admitted patient care 2014-15, Australian hospital statistics, health services series No. 68, cat. No. HSE 172, Canberra: AIHW 2016. 
18. Australian Institute of health and welfare (AlHW). principal diagnosis data cubes, 2017. Available: http://www.aihw.gov.au/hospitals-data/ principal-diagnosis-data-cubes/

19. Boorsma M, Joling KJ, Frijters DHM, et al. The prevalence, incidence and risk factors for delirium in Dutch nursing homes and residential care homes. Int J Geriatr Psychiatry 2012;27:709-15.

20. Taxis K, Kochen S, Wouters $\mathrm{H}$, et al. Cross-National comparison of medication use in Australian and Dutch nursing homes. Age ageing 2016;46:320-3.

21. McCusker J, Cole MG, Voyer P, et al. Prevalence and incidence of delirium in long-term care. Int $J$ Geriatr Psychiatry 2011;26:1152-61.

22. Dosa $\mathrm{D}$, Intrator $\mathrm{O}, \mathrm{McNicoll} \mathrm{L}$, et al. Preliminary derivation of a nursing home confusion assessment method based on data from the minimum data set. J Am Geriatr Soc 2007;55:1099-105.

23. Kiely DK, Bergmann MA, Murphy KM, et al. Delirium among newly admitted postacute facility patients: prevalence, symptoms, and severity. J Gerontol A Biol Sci Med Sci 2003;58:M441-M445.

24. Australian Bureau of Statistics. Population projections, Australia, 2012 (base) to 2101 [Internet], 2013. Available: http://www.abs.gov. au/ausstats/abs@.nsf/mf/3222.0. [Accessed 11 Dec 2017].

25. Barron EA, Holmes J. Delirium within the emergency care setting, occurrence and detection: a systematic review. Emerg Med $J$ 2013;30:263-8

26. McAvay GJ, Van Ness PH, Bogardus ST, et al. Older adults discharged from the hospital with delirium: 1-year outcomes. J Am Geriatr Soc 2006;54:1245-50.

27. Travers C, Byrne G, Pachana N, et al. Prospective observational study of dementia and delirium in the acute hospital setting. Intern Med J 2013;43:262-9.

28. Inouye SK, Rushing JT, Foreman MD, et al. Does delirium contribute to poor hospital outcomes? J Gen Intern Med 1998;13:234-42.

29. Independent Hospital Pricing Authority (IHPA). National Hospital Cost Data Collection, Public Hospitals Cost Report, Round 19 (Financial Year 2014-15) [Internet], 2017. Available: https://www. inpa.gov.au/publications/national-hospital-cost-data-collectionpublic-hospitals-cost-report-round-19-financial [Accessed 13 Dec 2017].

30. Australian Institute of Health and Welfare (AIHW). 2004 May 11. Health system expenditure on disease and injury in Australia 200001, cat. no. HWE 26 [Internet], 2004. Available: https://www.aihw.gov. $\mathrm{au} / \mathrm{reports} / \mathrm{health}$-welfare-expenditure/health-system-expenditureon-disease-and-injury-in/contents/table-of-contents [Accessed 13 Dec 2017]

31. National Health and Medical Research Council. Research funding statistics and data: all grants 2000-2016, 2017. Available: https:// www.nhmrc.gov.au/grants-funding/research-funding-statistics-anddata [Accessed 6 Dec 2017].

32. Department of Health. Annual Medicare statistics - financial year 1984-85 to 2015-16, 2016. Available: http://www.health.gov.au/ medicarestats [Accessed 6 Dec 2017].

33. Charles J, Miller G, Ng A. Management of psychosis in Australian general practice. Aust Fam Physician 2006;35.

34. Aged Care Financing Authority. Fourth Report on the Funding and Financing of the Aged Care Industry [Internet], 2016. Available: https://agedcare.health.gov.au/2016-report-on-the-funding-andfinancing-of-the-aged-care-industry [Accessed 11 Dec 2017]

35. Australian Bureau of Statistics. Labour Force, Australia, Jun 2016, Cat. No. 6202.0 [Internet], 2016. Available: http://www.abs. gov.au/AUSSTATS/abs@.nsf/DetailsPage/6202.0Jun\%202016? OpenDocument [Accessed 11 Dec 2017].

36. Australian Bureau of Statistics. Average Weekly Earnings, Australia, May 2017, Cat. No. 6302.0 [Internet], 2017. Available: http://
www.abs.gov.au/AUSSTATS/abs@.nsf/Lookup/6302.0Main+ Features1May\%202017? OpenDocument [Accessed 11 Dec 2017].

37. Vida S, Galbaud du Fort G, Kakuma R, et al. An 18-month prospective cohort study of functional outcome of delirium in elderly patients: activities of daily living. Int Psychogeriatr 2006;18:681-700.

38. Murray AM, Levkoff SE, Wetle TT, et al. Acute delirium and functional decline in the hospitalized elderly patient. $J$ Gerontol 1993;48:M181-M186.

39. KPMG Econtech. (2010). CGE analysis of the current Australian Tax system, report for the Australian government, 2010. Available: http:// www.taxreview.treasury.gov.au/content/html/commissioned_work/ downloads/KPMG_Econtech_Efficiency\%20of\%20Taxes_Final_ Report.pdf [Accessed 6 Dec 2017].

40. Cao L, Hosking A, Kouparitsas M, et al. Understanding the economywide efficiency and incidence of major Australian taxes, 2015. Available: http://www.apo.org.au/system/files/54294/apo-nid5429499131.docx [Accessed 6 Dec 2017].

41. Murray C, Lopez A. The Global Burden of Disease: a comprehensive assessment of mortality \& disability from diseases, injuries \& risk factors in 1990 \& projected to 2020, Volume 1, Global Burden of Disease \& Injury Series, Harvard: Harvard School of Public Health 1996.

42. Stouthard ME, Essink-Bot ML, Bonsel GJ, et al. Disability weights for diseases in the Netherlands. Rotterdam, The Netherlands: Department of Public Health, Erasmus University, 1997.

43. Cole MG, Ciampi A, Belzile E, et al. Persistent delirium in older hospital patients: a systematic review of frequency and prognosis. Age Ageing 2009;28:19-26.

44. Department of Prime Minister and Cabinet. Best practice regulation guidance note: value of statistical life, 2014. Available: https://www. pmc.gov.au/sites/default/files/publications/Value of Statistical Life guidance_note.pdf [Accessed 11 Dec 2017].

45. Brown L, Hansnata E, La HA. Economic cost of dementia in Australia, 2017. Available: https://staff.dementia.org.au/files/ NATIONAL/documents/The-economic-cost-of-dementia-in-Australia2016-to-2056.pdf [Accessed 6 Dec 2017].

46. Australian Institute of Health and Welfare. Australian burden of disease study: impacts and causes of illness and death in Australia 2011. 2016; AlHW Australian burden of disease study series No. 3. BOD 4. Available: https://www.aihw.gov.au/getmedia/d4df9251c4b6-452f-a877-8370b6124219/19663.pdf.aspx?inline=true [Accessed 6 Dec 2017].

47. Lundström M, Edlund A, Bucht G, et al. Dementia after delirium in patients with femoral neck fractures. J Am Geriatr Soc 2003:51:1002-6.

48. Davis DHJ, Muniz Terrera G, Keage $\mathrm{H}$, et al. Delirium is a strong risk factor for dementia in the oldest-old: a population-based cohort study. Brain 2012;135:2809-16.

49. Rockwood Ket al. The risk of dementia and death after delirium. Age Ageing 1999;28:551-6.

50. Organisation for economic cooperation and development. purchasing power parities (ppp), 2018. Available: https://data.oecd. org/conversion/purchasing-power-parities-ppp.htm [Accessed 15 Jun 2018].

51. Dasgupta M, Hillier LM. Factors associated with prolonged delirium: a systematic review. Int. Psychogeriatr. 2010;22:373-94.

52. Livingston $\mathrm{G}$, Sommerlad $\mathrm{A}$, Orgeta V, et al. Dementia prevention, intervention, and care. The Lancet 2017;390:2673-734.

53. Deloitte Access Economics. The economic value of informal care in Australia in 2015, 2015. Available: http://www.carersaustralia.com. au/storage/Access\%20Economics\%20Report.pdf [Accessed 20 Dec 2017]. 